\title{
'Hearing' alpine plants growing after snowmelt: ultrasonic snow sensors provide long-term series of alpine plant phenology
}

\author{
Yann Vitasse $\mathrm{e}^{1,2,3}$ (D) Martine Rebetez $^{1,2} \cdot$ Gianluca Filippa $^{4} \cdot$ Edoardo Cremonese $^{4}$. \\ Geoffrey Klein ${ }^{1,2} \cdot$ Christian Rixen $^{3}$
}

Received: 9 March 2016 /Revised: 1 June 2016 / Accepted: 15 July 2016 /Published online: 18 August 2016

(C) ISB 2016

\begin{abstract}
In alpine environments, the growing season is severely constrained by low temperature and snow. Here, we aim at determining the climatic factors that best explain the interannual variation in spring growth onset of alpine plants, and at examining whether photoperiod might limit their phenological response during exceptionally warm springs and early snowmelts. We analysed 17 years of data (1998-2014) from 35 automatic weather stations located in subalpine and alpine zones ranging from 1560 to $2450 \mathrm{~m}$ asl in the Swiss Alps. These stations are equipped with ultrasonic sensors for snow depth measurements that are also able to detect plant growth in spring and summer, giving a unique opportunity to analyse snow and climate effects on alpine plant phenology. Our analysis showed high phenological variation among years, with one exceptionally early and late spring, namely 2011 and 2013. Overall, the timing of snowmelt and the beginning of plant growth were tightly linked irrespective of the elevation of the station. Snowmelt date was the best predictor of plant growth onset with air temperature after snowmelt
\end{abstract}

Electronic supplementary material The online version of this article (doi:10.1007/s00484-016-1216-x) contains supplementary material, which is available to authorized users.

Yann Vitasse

yann.vitasse@wsl.ch

1 Institute of Geography, University of Neuchatel, Neuchatel, Switzerland

2 WSL Swiss Federal Institute for Forest, Snow and Landscape Research, Neuchatel, Switzerland

3 WSL Institute for Snow and Avalanche Research SLF, Group Mountain Ecosystems, Davos, Switzerland

4 Environmental Protection Agency of Aosta Valley, ARPA VdA, Climate Change Unit, Aosta, Italy modulating the plants' development rate. This multiple series of alpine plant phenology suggests that currently alpine plants are directly tracking climate change with no major photoperiod limitation.

Keywords Phenology · Snowmelt · Alpine vegetation · Climate warming · Growth onset · Photoperiod · Thermal time $\cdot$ Ultrasonic sensor

\section{Introduction}

The shift in the timing of seasonal events in plant and animal taxa is one of the most visible effects of global warming on ecosystems in temperate and boreal areas (Parmesan 2006; Reid et al. 2016; Walther 2003). Motivated by the wish to quantify the effects of climate warming on terrestrial ecosystems, phenology of temperate and boreal trees has been extensively documented over the last decades, and numerous phenological networks were established worldwide to collect long-term series of observations. The analysis of these series together with recent experimental studies manipulating temperature and photoperiod have considerably advanced knowledge about the interactions between the main environmental cues that drive spring phenology in temperate and boreal trees, namely chilling and forcing temperatures in winter and early spring, and photoperiod (e.g., Basler and Körner 2012; Clark et al. 2014; Fu et al. 2015a; Fu et al. 2015b; Fu et al. 2014; Gallinat et al. 2015; Laube et al. 2014; Zohner and Renner 2015), though the actual physiological processes are still not well accurately represented in current phenological models (Basler 2016; Clark et al. 2014).

No such long-term series of phenological data have been collected in herbaceous plants, especially in alpine plants, for which phenology remains poorly documented (but see a few 
long-term series of alpine plant flowering dates in, e.g., CaraDonna and Inouye 2015; Inouye 2008; Wielgolaski and Inouye 2013). Yet, global warming has been particularly intense in Arctic and alpine regions over the last decades and is expected to be more pronounced than on a global or northern hemisphere average during the next decades (Gobiet et al. 2014). In the Swiss Alps, the annual temperature warming observed during the last three decades was twice as high compared with what is reported at larger scale in the northern hemisphere (Böhm et al. 2001; Meehl et al. 2007; Rebetez and Reinhard 2008). In addition to higher trends on the regional scale, the warming process might be enhanced at higher elevations in the European Alps due to rapid modifications of numerous climatic, biological and physical parameters such as the snow albedo, water vapour changes and latent heat release or aerosols (Hernández-Henríquez et al. 2015; Mountain Research Initiative 2015). Alpine regions are therefore particularly inclined to undergo intense modifications including upslope migration of plant species together with modification in the composition of plant communities (Gottfried et al. 2012; Grabherr et al. 1994; Parolo and Rossi 2008; Pauli et al. 2012).

The presence of a long-lasting snow cover, insulating plants from air temperature, complicates phenological studies conducted in the alpine or arctic tundra. Hence, in such ecosystems, snow depth data and temperatures recorded at the plant site are essential for understanding the relationship between alpine plant phenology and climatic parameters (Wipf and Rixen 2010). The timing of snowmelt in combination with temperature and photoperiod is often seen as the main driver of alpine and Arctic plant phenology (Hülber et al. 2010; Keller and Körner 2003; Wipf et al. 2009), and a tight link between the date of snowmelt and the beginning of plant growth has been documented in Arctic and alpine ecosystems (e.g., Bjorkman et al. 2015; Chen et al. 2015; Cornelius et al. 2013; Ernakovich et al. 2014; Filippa et al. 2015; Jonas et al. 2008). While in the Arctic, the phenology of plants is expected to advance in relation to earlier snowmelt and warmer air temperature (Bjorkman et al. 2015), the phenological shift may be more moderate in alpine areas because of a possible limitation by the photoperiod (Ernakovich et al. 2014; Iler et al. 2013). In fact, an experimental study using 33 alpine plant species in the Central Alps revealed that about half of them could be under strong control of photoperiod in their spring phenology (Keller and Körner 2003). The control of phenology by photoperiod is supposed to be more moderate in plant species inhabiting snowbed conditions, for which the timing of snowmelt would constitute the main driver compared to species growing in wind-exposed habitats with earlier and stochastic snowmelt (Hülber et al. 2010). However, only very few long-term series of phenology have been yet analysed in alpine regions to assess their phenological sensitivity to temperature, snowmelt timing and photoperiod (but see Anderson et al. 2012; Iler et al. 2013).
In the European Alps, warmer winter temperatures have affected snow cover up to the elevation of 1500 to $2000 \mathrm{~m}$ asl (Laternser and Schneebeli 2003; Scherrer and Appenzeller 2006). At higher elevations, the impact of warmer temperatures on snow pack is usually less pronounced because most of the winter temperatures at these elevations ranged below the melting point (Serquet et al. 2011; Serquet et al. 2013). However, snowpack and snowfall data at higher elevations and after the month of April were usually too sparse to provide robust results, but preliminary analysis of several long-term series of snow data in the Swiss Alps shows evidence for earlier snowmelt and thinner snowpack irrespective of elevations from 1139 to $2540 \mathrm{~m}$ asl (Klein et al., in revision). A longer growing season induced by earlier snowmelt is not necessarily an advantage for plant fitness because it generally induces a higher exposure of plants to potentially damaging freezing temperatures or to early development in sub-optimal climatic conditions, as shown in alpine dwarf shrubs (Wheeler et al. 2014) and in herbaceous plants (Galvagno et al. 2013; Inouye 2008). Interestingly, based on fitness-related traits, earlier snowmelt was shown to decrease the overall performance of Salix herbacea in the Swiss Alps, in spite of the increase of the growing season length (Sedlacek et al. 2016; Sedlacek et al. 2015; Wheeler et al. 2016). Yet, some plant species that are adapted to thin snow (e.g., Loiseleuria procumbens) may be more advantaged by earlier snowmelt than plants that generally develop in snowbeds (Wipf et al. 2009). A major change in the timing of snowmelt is therefore expected to lead to dramatic changes in plant community composition (Wahren et al. 2005). As a matter of fact, the heterogeneity of snowmelt in alpine habitats largely reflects the difference in plant community composition with some species more adapted to longlasting cover and others to more wind-exposed conditions (Julitta et al. 2014; Walker et al. 1993). However, experimental snow removal has shown only little advance in the reproductive phenology in alpine species inhabiting snowbed conditions (Petraglia et al. 2014). Long-term observations of vegetation onset in alpine plants would help to clarify whether the photoperiod may become a limiting factor under exceptionally early snowmelt years but are to date clearly lacking (but see Bjorkman et al. 2015; Iler et al. 2013).

Here, we used a unique dataset, recorded in the Swiss Alps at elevations ranging from 1560 to $2450 \mathrm{~m}$ asl, that combines climatic parameters such as snow depth, air and soil temperature along with phenological parameters derived from the ultrasonic sensors mounted at each weather station over the period 1998 2014. We tested two hypotheses. First, we hypothesised that soil and surface temperatures as well as the date of snowmelt, rather than mean air temperature, are the best predictors for alpine spring phenology. Second, we expected to observe a longer time lag between snowmelt and vegetation onset during warm springs with early snowmelt as a consequence of lower temperatures following early snowmelt (compared to later snowmelt), slowing 
down plant development, rather than as a consequence of a photoperiodic limitation.

\section{Materials and methods}

\section{Study sites}

All climatic and phenological parameters were extracted from automatic weather stations that belong to the IMIS network setup by the Swiss Federal Institute for Snow and Avalanche Research (SLF) in the 1990s. These automatic meteorological stations monitor and relay to a server every $30 \mathrm{~min}$ several parameters such as snow depth, air temperature, soil surface temperature, ground temperature recorded just above the soil but covered by rocks, and solar radiation. Most of the sites are meadows moderately grazed by cattle, a common type of ecosystem for the Swiss Alps. The ultrasonic sensor (SR50, Campbell Scientific, USA) mounted on each weather station for measuring snow depth was also shown to track vegetation growth accurately after snowmelt (Jonas et al. 2008). In fact, the ultrasonic sensors were sensitive to plants within a radius of $75 \mathrm{~cm}$ below the aiming point for a sensor situated $6 \mathrm{~m}$ above ground. The sensor picks up the reflection of leaves or flowers if they occupied a minimum horizontal surface of $4 \%$ of the sensor footprint, and its accuracy is about $2 \mathrm{~cm}$. Note that the sensor was set up to respond to the nearest target (i.e., for the purpose of this study, the tallest plants). Hence, the data from the IMIS network provide a unique opportunity to analyse snow and climate effects on timing and growth of alpine vegetation over a long time period. As the stations were originally installed to record snow depth and climatic parameters, many of them are located in rocky terrain with no or very short plants growing below the ultrasonic sensor. Therefore, among the 123 weather stations that belong to this network, we selected 35 stations for which a clear signal of vegetation was detected by the ultrasonic sensor (localisation of the weather stations on Fig. 1). All the 35 sites are in open and flat remote areas, ranging from 1560 to $2450 \mathrm{~m}$ asl and generally not exposed to wind. Vegetation surveys, conducted in summer 2015 on the surface covered by the ultrasonic sensors, indicate that graminoid species are largely dominant at most of the stations, especially above $2000 \mathrm{~m}$ (in which they are dominant in $\sim 85 \%$ of the selected stations), whereas the proportion of forbs increases towards lower elevations (Table S1). Number of species growing below the ultrasonic sensors varied between three and 35 depending on the station, with an average of 16 species per station (Table S1). At the time of the vegetation survey, the tallest species covering more than $4 \%$ of sampled surface (i.e., likely to be tracked by the ultrasonic sensor) were always represented by graminoid species (e.g., Festuca rubra aggr., Poa alpina or Carex sempervirens) at the 15 highest selected stations, whereas forbs were the tallest species in six of the ten lowest stations (e.g., Rumex alpestris, Rumex alpinus or Ranunculus aconitifolius, Table S1).

\section{Data analysis}

\section{Extraction of the phenological parameters}

We used snow depth data recorded every $30 \mathrm{~min}$ by the ultrasonic sensors to derive the dates of snowmelt. Figure 2 shows the expected signal of snow and vegetation height detected from the ultrasonic sensors. We define the snowmelt date after the end of the meteorological winter (1st of March), as the first snow-free day after the last snow cover sequence during at least 1 month. Snowmelt dates correspond to the period when soil temperature becomes positive and starts varying significantly. Height recorded by the ultrasonic sensor after snowmelt was daily aggregated and used to estimate vegetation height. Daily median vegetation height time series were pretreated as following: we first deleted the data occurring 5 days earlier than the snowmelt date and after the day 250 of the year (7th of September) to avoid inclusion of snow depth data from the following winter season. We then computed the minimum vegetation height of the first 6 days after snowmelt and shift the following data by this number. This step was needed to account for potentially uncalibrated snow-depth sensors. Phenological parameters were extracted from a growth curve fitted to the observed data. To improve fitting accuracy, we generated an artificial baseline with 30 data points of $0 \mathrm{~cm}$ vegetation height before snowmelt and an artificial plateau replicating maximum observed vegetation height after the maximum height detected by a spline function. This was particularly useful for the maximum plateau because vegetation growing below the ultrasonic sensors was often grazed during the growing season (as shown in Fig. 3). To mimic a credible noise to the data, the random plateau was generated using the mean and the standard deviations of the five daily vegetation height values occurring after the maximum height determined by the spline fitting. After this pre-treatment, we then applied a statistical method to extract the phenological parameters using the logistic (Eq. 1), the Gompertz (Eq. 2) and the modified Gompertz models (Eq. 3), allowing a second increase after the function enters a first saturation plateau.

$$
\begin{aligned}
y(t)= & \frac{A}{1+\exp \left(\frac{4 \mu}{A}(\lambda-t)+2\right)} \\
y(t)= & A \cdot \exp \left[-\exp \left(\frac{\mu \cdot \exp (1)}{A}(\lambda-t)+1\right)\right] \\
y(t)= & A \cdot \exp \left[-\exp \left(\frac{\mu \cdot \exp (1)}{A}(\lambda-t)+1\right)\right] \\
& +A \cdot \exp \left(\alpha\left(t-t_{\text {shift }}\right)\right)
\end{aligned}
$$




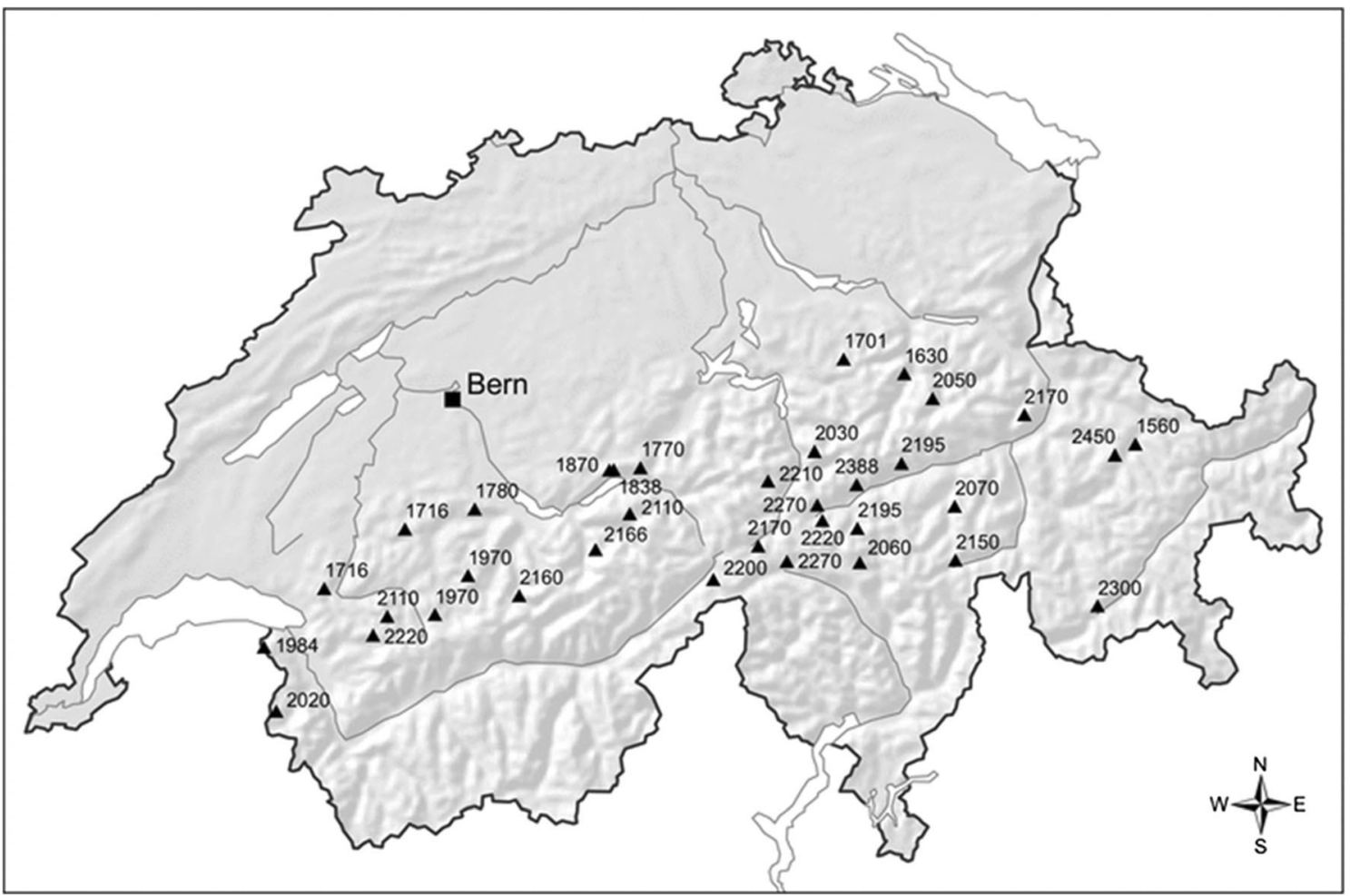

Fig. 1 Localization and elevation of the 35 weather stations used in the analyses to extract phenological and meteorological data

where $A$ is the maximum vegetation height $(\mathrm{cm}), \mu$ is the maximum growth rate (cm/day), $\lambda$ is the start of growth based on the inflexion point of the fitted curve (day of the year), $t_{\text {shift }}$ and the scaling factor $\alpha$ control the location (time) and the strength (slope) of the second increase in the modified Gompertz model.

Models were optimized by non-linear least squares methods using the R-package 'grofit'. For each year and site, the best model was selected according to Akaike Information Criterion (AIC) values. Confidence intervals for all parameters are estimated by using a non-parametric bootstrap method (Efron and Tibshirani 1994).

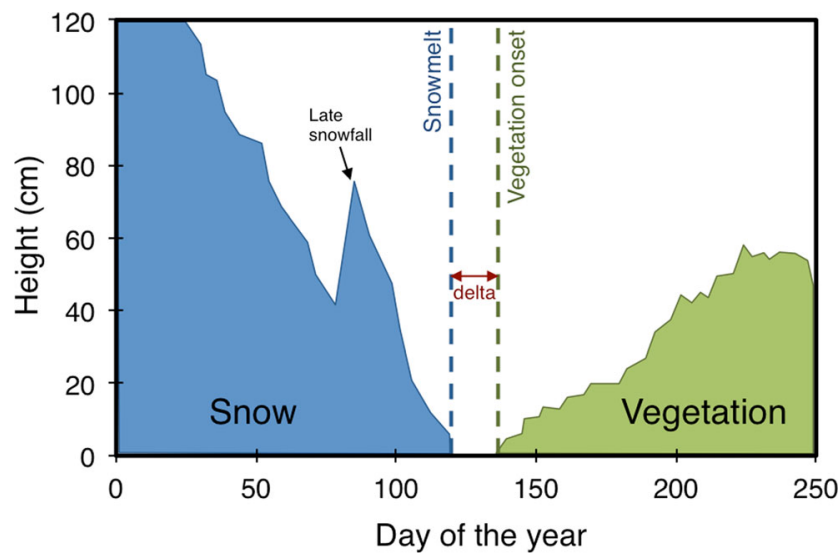

Fig. 2 Conceptual diagram showing the expected theoretical signal of snow and vegetation detected by the ultrasonic sensors
As the focus of the present paper is the beginning of vegetation in relation to climatic parameters and snowmelt dates, we present only the start of growth $(\lambda)$ and the time lag between snowmelt and the start of growth $(\Delta)$ and disregarded the other parameters (Fig. 2). After parameter estimation, filtering procedures were applied to remove unreliable values and inaccuracies. We discarded all data for which: $A$ was lower than $4 \mathrm{~cm}$ because it would be too close to the accuracy resolution of the sensor (15 discarded site-years), $\Delta$ was negative (four discarded site-years), $\lambda$ was found later than 1st of August to avoid inclusion of early snowfall (five discarded site-years), and finally when the standard error of $\lambda$ was higher than 3 days, allowing us to keep only robust extracted phenological parameters (35 discarded site-years). In addition, visual inspection revealed inaccurate site-years that had to be removed manually, mostly because the vegetation signal was mixed up with late snowfall events ( 23 site-years). The selected 35 stations provided 322 site-years of phenological records, covering 17 winter/spring seasons during the period 19982014. These data were then used in all further analyses. Among these 35 sites, $43 \%$ (15) had data of 3 to 7 years, $31 \%$ (11) 8 to 12 years and $26 \%$ (9) more than 12 . These last nine stations were examined in more detail to test a possible photoperiodic limitation during the warmest springs over the study period. The earliest vegetation onset dates occurred during the warmest spring in 2011 and the latest during the coldest spring in 2013. These 2 years are shown with red squares and blue triangles, respectively in all graphs, in order 


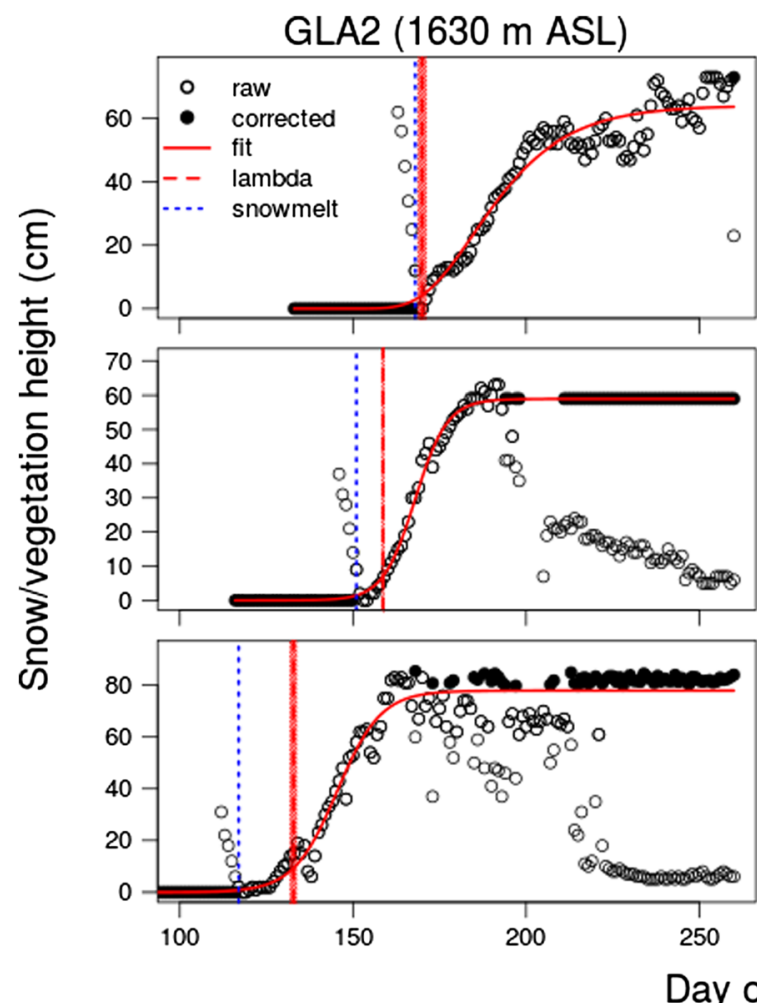

Day of the year
Fig. 3 Example of the fitting procedure applied to obtain the vegetation growth parameters for a low- and high-elevation station (GLA2, $1630 \mathrm{~m}$ asl and VAL2, $2270 \mathrm{~m}$ asl) for a warm (2011), intermediate (2009) and cold spring (2013). Lambda is the vegetation onset (day of the year) and has been determined based on the inflexion point of the logistic,

to visualize the effect of extreme warm and cold years on alpine plant phenology. Figure 3 shows examples of the fitting procedure that allow us to extract phenological parameters for a low- and a high-elevation station during three contrasting years (warm spring: 2011, intermediate: 2009 and cold spring: 2013).

\section{Thermal time required for vegetation onset}

For each site and year, we computed thermal time above $0{ }^{\circ} \mathrm{C}$ required from the date of snowmelt to the vegetation onset using daily mean air temperature data (Eq. 4)

$T T_{i}=\sum_{d_{0}}^{d_{1}}\left(T_{i, d}-T_{b}\right) I\left(T_{i, d}>T_{b}\right)$

where $T T_{i}$ is the thermal time requirement to initiate vegetation onset, which occurs for a given station $i$ on day of the year $d_{1}$. Ti, $d$ is the mean temperature for a given station $i$ on day $d$, $T_{b}$ is the temperature threshold required to accumulate forcing temperatures, and $I()$ is an indicator equal to 1 when its argument is true and 0 otherwise. Thermal time counting begins on day $d_{0}$ which is the day of the year corresponding to the snowmelt date for a given station $i$.

As alpine plants may be photosynthetically active during periods with low temperature (Kimball et al. 1973), we used a
Gompertz or modified Gomperts models that fitted the best to the data. The Gompertz model was used to fit the vegetation height in the station GLA2 in 2013, whereas logistic models were used for all the other five examples

threshold temperature value $\left(T_{b}\right)$ of $0{ }^{\circ} \mathrm{C}$. Calculations using other threshold temperatures (from $2{ }^{\circ} \mathrm{C}$ to $5{ }^{\circ} \mathrm{C}$ ) led to similar results, and thus are not shown.

\section{Statistical analysis}

To test which climatic parameters are the best predictors of vegetation onset dates across stations and years, we applied a linear mixed effect model accounting for the variation among stations as a random effect (as different plant communities with potentially different thermal requirements for vegetation onset can grow at the different study stations) and the tested climatic parameter as a fixed effect. We then plotted the predicted values from these models against the observed values and compared the accuracy of the predictions based on the root mean square errors (RMSE) and the $\mathrm{R}^{2}$ of the linear regressions between predicted and observed values. Residuals were visually checked for normality and homoscedasticity and were found to respect model assumptions for any climatic parameter. We did not combine several climatic parameters as fixed effects in the model because they were collinear and we aimed to compare the predictive power of each factor separately. We selected the following 
explanatory variables as fixed effects in the models across stations and years: mean spring air temperature from March to May (temperature sensor at $7 \mathrm{~m}$ height), mean monthly (March to June) air temperature, mean monthly (March to June) soil surface and ground temperature and the snowmelt dates.

Within individual stations, simple linear regressions between above-mentioned climatic parameters and vegetation onset dates were fitted: the explanatory power of each climatic parameter was evaluated using coefficients of determination.

To test the hypothesis of a photoperiodic limitation over spring phenology and whether plant development is slower after early snowmelt, we used an exponential model to test or evaluate the influence of the date of snowmelt on the lag between snowmelt and vegetation onset. A significant relationship can be the result of two nonexclusive explanations: (i) a genuine photoperiodic limitation, or (ii) a non-proportional effect between the temperature course in spring and the course of plant phenology, that is, temperatures following the snowmelt are colder during years with very early snowmelt than during years with intermediate and late snowmelt. The apparent relationship may reflect the different sensitivity of the different vegetation communities to snowmelt and temperatures. The vegetation found at low-elevation sites, having usually early snowmelt, may require higher thermal time or longer time lag after snowmelt to start their growth. To test these two hypotheses, we first calculated the mean air temperature during a 15-day period after the snowmelt dates for each site and year (15 days correspond to the mean time lag between snowmelt and vegetation onset across stations and years). We then equally separated the site-years into early, intermediate and late snowmelt dates to check whether temperatures following early snowmelt are also colder, potentially explaining the longer time lag for vegetation onset. Second, we tested whether we do have a relationship between the thermal time to grow and the snowmelt dates over the years for stations having the most available data (nine stations with more than 12 years available) and finally for all stations (Table 1). A photoperiod limitation would extent the lag between snowmelt and vegetation onset and increase the thermal time to trigger vegetation onset during exceptionally early snowmelt, whereas a pure thermal effect is expected if the thermal time remains unchanged irrespective of the lag between snowmelt and vegetation onset. We used linear regressions rather than exponential relationships because the linear model performed better than the exponential model in the cases when a significant linear relationship was detected. The higher performance of linear models is likely due to the limited number of data (maximum 17 for a given station) and we expected individual stations' results to be either in the increasing part of the non-linear relationship or in the plateau of the exponential model that includes all the nine stations.

All data analyses were performed using Rstudio version 0.99.489 (R Core Team 2015).

\section{Results}

\section{Climatic and phenological variability}

While mean spring temperatures, snowmelt and vegetation onset showed no significant temporal trends over the study period (1998-2014), a high interannual variability was detected (Fig. 4). During the study period, mean spring (March-April-May) temperature ranged between -0.1 and $3.6{ }^{\circ} \mathrm{C}$ with a rather homogeneous period from 1998 to $2003\left(0-2{ }^{\circ} \mathrm{C}\right)$ and higher variation afterwards. Remarkably, the two most extreme years in terms of spring temperatures occurred in a period of 3 years (2011-2013), 2011 being the warmest and 2013 the coldest. The date of snowmelt and vegetation onset followed the same general pattern as spring temperature. The earliest dates of snowmelt and vegetation onset detected over the study period were in 2011 (snowmelt 2011: DOY 119, i.e., about a month earlier than the average of the other years; vegetation onset 2011: DOY 141, i.e., about 3 weeks earlier than the average of the other years), whereas the coldest spring occurred in 2013 $\left(-0.02{ }^{\circ} \mathrm{C}\right)$ and coincided with the latest snowmelt and vegetation onset (DOY 164 and DOY 177, respectively, Fig. 4). On average, the greatest difference of the date of vegetation onset for an individual station across years was about 38 days, reaching up to more than 50 days in a few stations (data not shown).

\section{Best climatic predictors of alpine spring phenology}

While air temperature in April or May explains on average less than $40 \%$ of the variation of the vegetation onset dates within stations, soil surface and ground surface temperature in May explain 57 and $61 \%$ of the variation (Table S2). The best predictor of vegetation onset for individual stations over the years is snowmelt dates $\left(R^{2}=0.72\right.$, Table S2). Using the linear mixed effect model accounting for the variability among stations, we found that more than $75 \%$ of the total variation of the timing of the vegetation onset can be explained by the following parameters: the snowmelt dates $\left(\mathrm{R}^{2}=0.85\right.$, RMSE $=5.9$ days, overall the mean time lag between snowmelt dates and vegetation onset across stations and years was 15.2 days), the mean soil temperature in May $\left(\mathrm{R}^{2}=0.76\right.$, $\mathrm{RMSE}=7.7$ days $)$ and the mean surface temperature in May $\left(\mathrm{R}^{2}=0.75\right.$, RMSE $=8.0$ days, Fig. 5$)$. The mixed effect model using spring air temperature as fixed 
Table 1 Linear relationships between (1) the time lag snowmelt date-vegetation onset $(\Delta)$ and snowmelt dates, (2) between the thermal time $>0{ }^{\circ} \mathrm{C}$ accumulated from snowmelt to vegetation onset and snowmelt dates.

\begin{tabular}{|c|c|c|c|c|c|c|}
\hline ID & $\begin{array}{l}\text { Elevation } \\
\text { (m asl) }\end{array}$ & $n$ & $\begin{array}{l}\mathrm{R}^{2} \Delta \\
\text { vs. snowmelt }\end{array}$ & $P$ value & $\begin{array}{l}\mathrm{R}^{2} \text { Thermal time } \\
\text { vs. snowmelt }\end{array}$ & $P$ value \\
\hline SLF2 & 1560 & 14 & 0.45 & 0.008 & 0.00 & 0.991 \\
\hline GLA2 & 1630 & 13 & 0.77 & $<0.001$ & 0.48 & 0.008 \\
\hline YBR2 & 1701 & 5 & 0.68 & 0.087 & 0.09 & 0.628 \\
\hline ALI2 & 1716 & 10 & 0.62 & 0.007 & 0.74 & 0.001 \\
\hline JAU2 & 1716 & 9 & 0.64 & 0.010 & 0.04 & 0.603 \\
\hline SCB2 & 1770 & 13 & 0.19 & 0.136 & 0.00 & 0.855 \\
\hline STH2 & 1780 & 12 & 0.68 & 0.001 & 0.77 & $<0.001$ \\
\hline ROA4 & 1838 & 3 & 0.14 & 0.751 & 0.82 & 0.281 \\
\hline ROA2 & 1870 & 17 & 0.26 & 0.038 & 0.03 & 0.527 \\
\hline FAE2 & 1970 & 17 & 0.52 & 0.001 & 0.07 & 0.294 \\
\hline LAU2 & 1970 & 12 & 0.23 & 0.111 & 0.04 & 0.531 \\
\hline GRA2 & 1984 & 4 & 0.29 & 0.462 & 0.02 & 0.861 \\
\hline ILI2 & 2020 & 9 & 0.34 & 0.098 & 0.09 & 0.440 \\
\hline SCA2 & 2030 & 11 & 0.01 & 0.813 & 0.07 & 0.419 \\
\hline ELM2 & 2050 & 5 & 0.00 & 0.923 & 0.03 & 0.777 \\
\hline DTR2 & 2060 & 8 & 0.08 & 0.492 & 0.10 & 0.449 \\
\hline VLS2 & 2070 & 10 & 0.17 & 0.242 & 0.09 & 0.391 \\
\hline FIR2 & 2110 & 7 & 0.21 & 0.306 & 0.01 & 0.837 \\
\hline OBM2 & 2110 & 5 & 0.02 & 0.816 & 0.21 & 0.444 \\
\hline HTR2 & 2150 & 11 & 0.32 & 0.072 & 0.00 & 0.844 \\
\hline FIS2 & 2160 & 11 & 0.00 & 0.866 & 0.00 & 0.903 \\
\hline LHO2 & 2166 & 5 & 0.00 & 0.979 & 0.25 & 0.389 \\
\hline TAM3 & 2170 & 4 & 0.18 & 0.571 & 0.00 & 0.988 \\
\hline URS2 & 2170 & 14 & 0.24 & 0.079 & 0.00 & 0.999 \\
\hline PUZ2 & 2195 & 5 & 0.37 & 0.276 & 0.14 & 0.532 \\
\hline TUM2 & 2195 & 4 & 0.22 & 0.528 & 0.65 & 0.196 \\
\hline OBW3 & 2200 & 11 & 0.20 & 0.166 & 0.00 & 0.937 \\
\hline MEI2 & 2210 & 4 & 0.28 & 0.473 & 0.02 & 0.859 \\
\hline CHA2 & 2220 & 14 & 0.26 & 0.064 & 0.00 & 0.835 \\
\hline TUJ3 & 2220 & 7 & 0.02 & 0.742 & 0.19 & 0.325 \\
\hline TUJ2 & 2270 & 15 & 0.11 & 0.236 & 0.03 & 0.549 \\
\hline VAL2 & 2270 & 16 & 0.11 & 0.204 & 0.00 & 0.969 \\
\hline LAG3 & 2300 & 7 & 0.32 & 0.190 & 0.22 & 0.287 \\
\hline LUM2 & 2388 & 6 & 0.47 & 0.131 & 0.31 & 0.247 \\
\hline DAV3 & 2450 & 4 & 0.29 & 0.465 & 0.06 & 0.758 \\
\hline
\end{tabular}

All significant linear relationships at $P \leq 0.1$ are highlighted in bold. For the relationship 1, this was found significant in 11 stations, mainly at lower elevations, whereas in the lrelationship 2 , this was significant in only three stations variable explained less of the variation $(66 \%, \mathrm{RMSE}=9.0$, Fig. 5). Every degree increase advanced the vegetation onset by about 4 days using soil surface and ground temperature in May and by 6.3 days using spring air temperature, whereas a delay of 10 days in snowmelt delayed the vegetation onset by 7.5 days. Unexpectedly, the strength of the relationship between the snowmelt dates and the vegetation onset does not decline or increase, neither with elevation nor with mean spring temperatures across years of the corresponding stations (data not shown). Snowmelt is hence an excellent proxy to predict vegetation onset irrespective of the elevation.

\section{Little evidence for photoperiod limitation}

Across stations and years, the time lag between snowmelt and the vegetation onset increased exponentially towards earlier snowmelt (i.e., at low-elevation sites or during the warmest springs), potentially suggesting a photoperiod limitation (Fig. 6). However, the mean temperature 


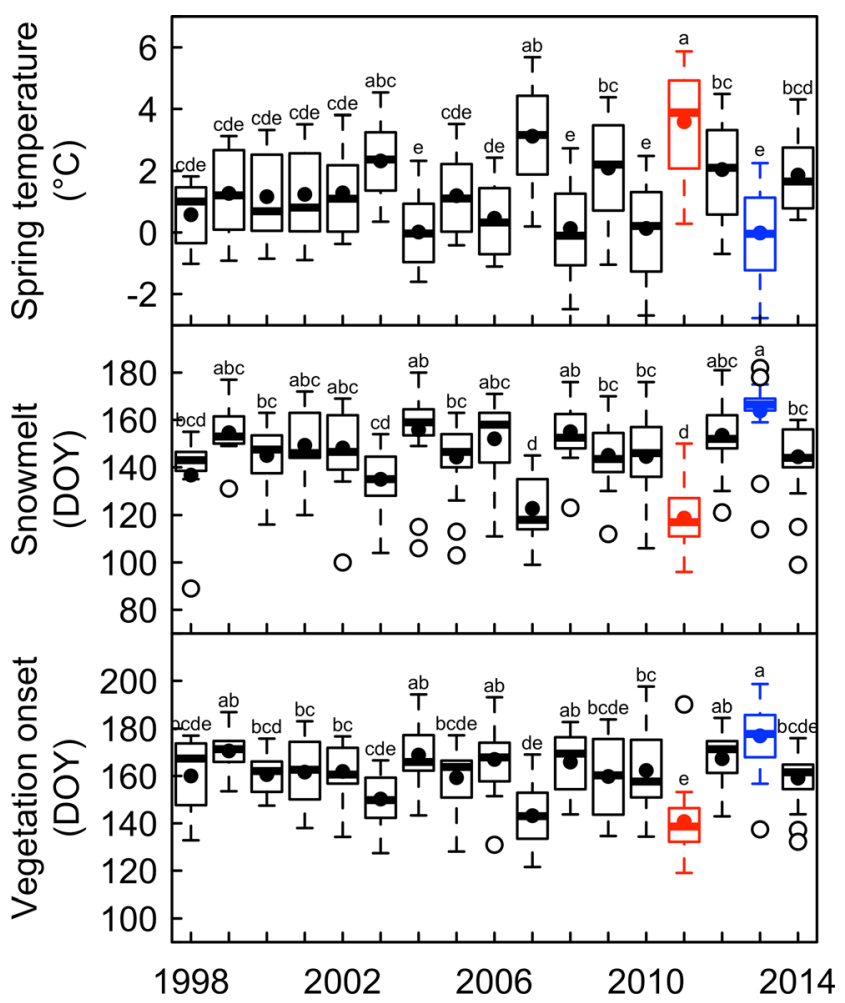

Fig. 4 Spring temperature, snowmelt and the timing of vegetation onset over the study period. The box-plots show median, first and third quartiles and extremes values (open circles) of the considered parameter. Filled circles indicate the mean. Different letters means significant differences as tested by an ANOVA following by Tukey's honestly significant difference (HSD) tests

occurring during 15 days following the snowmelt was also substantially colder in early snowmelt years than in intermediate or late snowmelt years (Fig. 7), so that the plants required more time to accumulate the same amount of heat during early snowmelt years.

At the individual station scale, we detected a significant linear increase in the time lag from snowmelt to vegetation onset $(\Delta)$ when snowmelt dates occurred earlier in six out of the nine stations having more than 12 years of available data (at $p<0.10$ ), mostly at lower elevations (Fig. 8). Across the 35 stations, this relationship was significant for $31 \%$ of the stations (11 out of the 35 stations), especially at lower elevations (Table 1). However, when taking into account the temperature course in spring by using the thermal time above $0{ }^{\circ} \mathrm{C}$ from snowmelt to vegetation onset, only one of the nine stations having more than 12 years of data presented a significant linear relationship (Fig. 8), and three out of 35 stations (8.5\%). These three stations were located at the lowest elevations within our dataset (below $1800 \mathrm{~m}$, Table 1). This result indicates the absence of a strong photoperiodic limitation in recent climatic conditions, but rather supports the non-proportional increase of temperature over the course of phenology in spring (i.e., slower and faster accumulation of the same amount of heat in early- and late-melting years, respectively, Fig. 7). Thus, at the majority of the stations, the time lag between snowmelt and vegetation onset increases with earlier snowmelt as a result of the nonproportional increase of temperature over the course of spring, while at a few stations $(8.5 \%)$ the vegetation might be limited by a too-short photoperiod during warm springs (early snowmelt).

\section{Discussion}

The network of weather stations analysed here was initially set up to monitor the snow cover in the Swiss Alps. Our results show that it also provides a unique long-term and continuous dataset for tracking the spring phenology of alpine plants. Overall, in contrast to spring air temperature, the timing of snowmelt is an excellent proxy to predict the beginning of vegetation growth, as it explained $85 \%$ of the total variation observed across years and sites with an accuracy of less than 6 days. No significant shift of alpine plant phenology was detected over the last 18 years, which is in fact consistent with climatic data showing no major trends in spring air temperature and snowmelt over the study period (Reid et al. 2016). In fact, the study period was too short to detect robust temporal trends, and it occurred after the major regime shift (1980s) observed for Earth's major biophysical phenomena including temperature and phenology (Reid et al. 2016). Unexpectedly, we found that, at the majority of the study sites, photoperiod did not play a significant role in triggering vegetation onset over the last two decades, as no significant increase in heat accumulation required for vegetation onset was detected during early snowmelt years (warmer springs).

The observed advance of spring onset in response to climate warming is slowing down in temperate trees, likely as a consequence of a lack of chilling for dormancy release and photoperiod constrains (Fu et al. 2015b). In contrast, the effect of global change on alpine plant phenology is expected to be stronger as alpine plants are beneath snow cover during winter, providing a long duration of chilling temperature. We could indeed reasonably assume that the endodormancy of alpine plants is released well before snowmelt, so that alpine plants are directly responsive to warm air temperature once snow has melted. In support of that assumption, we found that the date of snowmelt is the best proxy for predicting the beginning of the vegetation growth, while the temperature after the snowmelt modulates the time lag before growth initiation. This is in line with a recent study conducted on the alpine vegetation of the Qinghai-Tibetan Plateau (Chen et al. 2015) and a recent experimental study manipulating both snow cover and temperature in the Arctic (Livensperger et al. 2016). Yet, physiologically, the temperature surrounding the plant meristem tissues is most important. After snowmelt, the local temperature around the plant changes dramatically as the plant tissues become coupled with surface air temperature. It is then not surprising to obtain higher correlations when using soil or surface temperature over a short period before vegetation onset, rather than standard mean spring air 


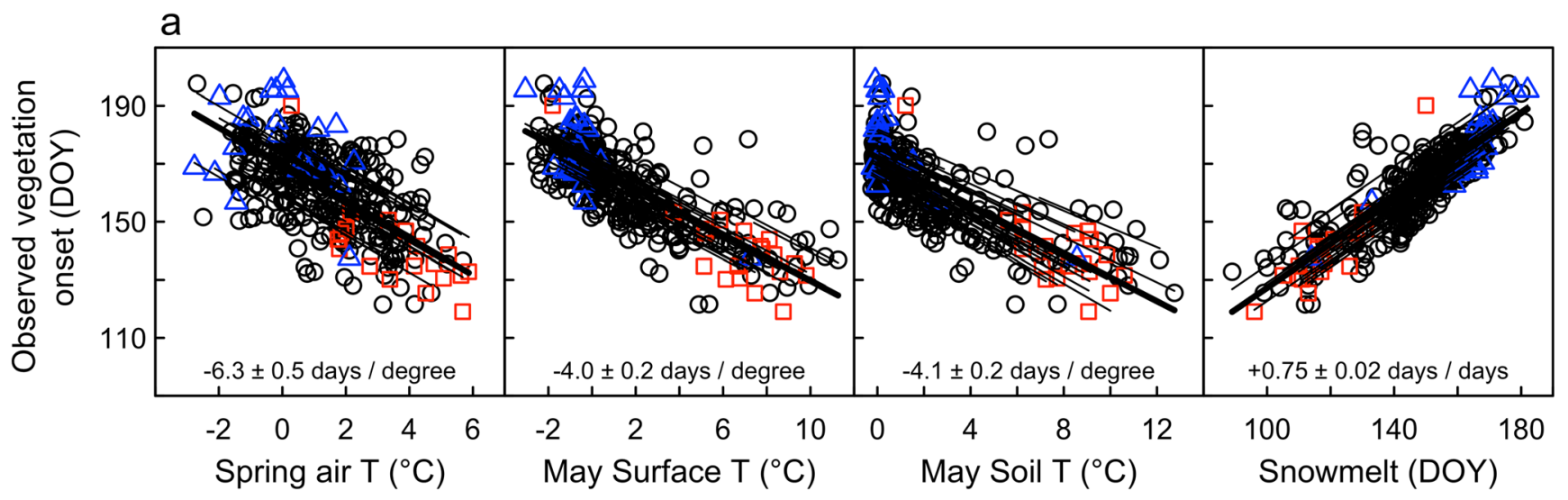

b

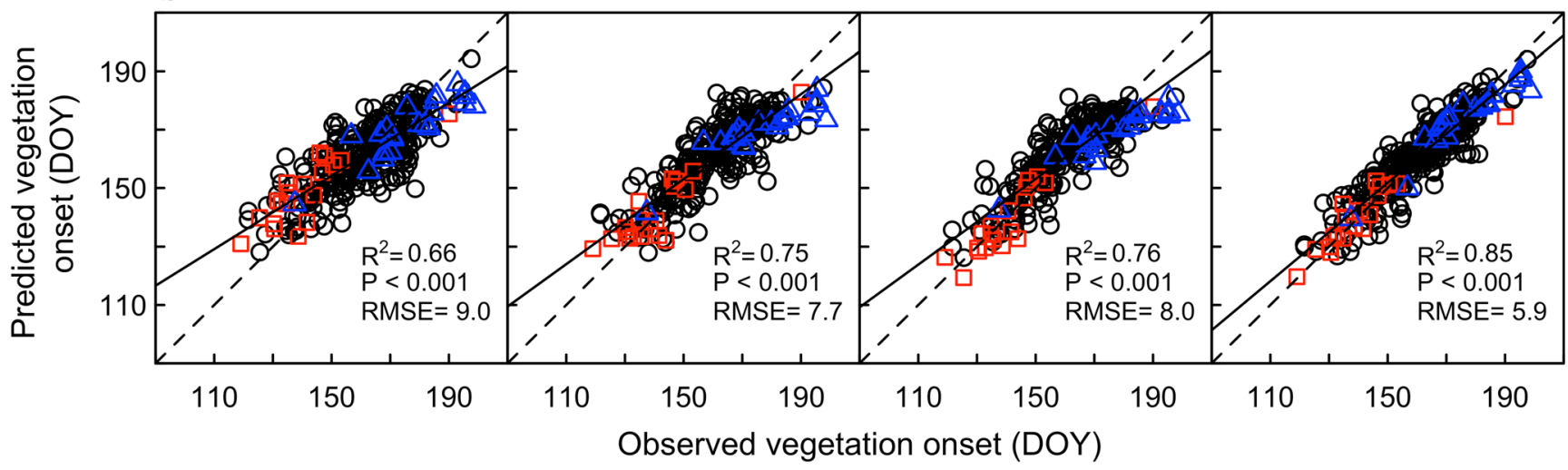

Fig. 5 a. Relationships between the best explanatory variables and the vegetation onset using the linear mixed effect model. The mean slope value of the model is reported at the bottom of each graph. b. Comparison of predicted vegetation onset using the linear mixed effect model versus 'observed' vegetation onset (extracted from the ultrasonic sensor) using the best explanatory variables. Spring air temperature is the

temperature, because the former two capture both snow conditions (temperature around zero under snowpack) and variation in air temperature once snow has melted. For instance, the

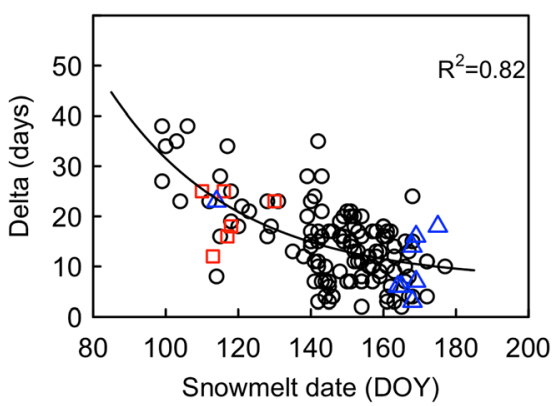

Fig. 6 Time lag between snowmelt and vegetation onset in relation to the timing of snowmelt. Only data of the nine stations having more than 12 years are plotted. A nonlinear model was fitted between the time lag snowmelt-vegetation onset and the timing of snowmelt $(y=a * \exp .(-m *$ $\mathrm{x})+\mathrm{b})$, with parameters for the exponential model: $\mathrm{a}=428 \pm 457$ $(P=0.35) ; \mathrm{b}=7.1 \pm 3.8(P=0.06) ; \mathrm{m}=0.029 \pm 0.011(P=0.013)$. The year 2011 is represented in red and the year 2013 is represented in blue. For black and white print: The year 2011 is represented with squares and the year 2013 is represented with triangles mean of daily mean temperature from 1 March to 31 May. The identity line is reported together with the $\mathrm{R}^{2}$, the $P$ value of the linear regression and the RMSE. The year 2011 is represented in red and the year 2013 in blue to visualize better the effect of extreme warm and cold springs. For black and white print: The year 2011 is represented with squares and the year 2013 is represented with triangles

correlation between soil or surface ground temperature in May and vegetation onset was much higher than if using air temperature of the same month (Table S2).

Within similar elevation ranges, temperatures in alpine terrain can widely vary over very short distances due to rapid change in the microtopography (slopes, ridges, depressions, rocks, cracks, etc.), leading to a mosaic of life conditions for

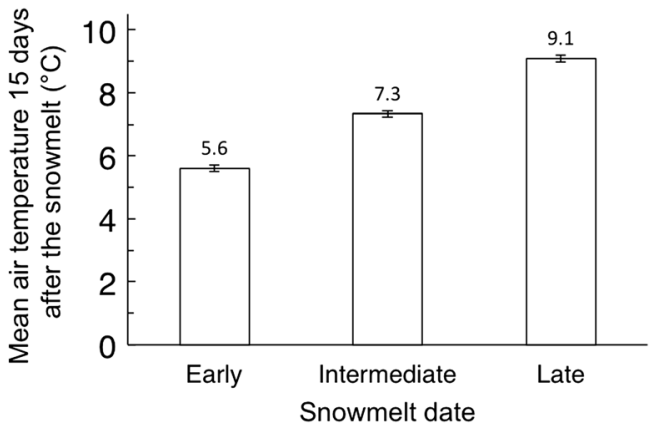

Fig. 7 Mean air temperature 15 days after the snowmelt (corresponding to the mean delay between snowmelt and vegetation across all stations and years) by clustering years by early, intermediate and late snowmelt using the quantile 33 and $66 \%$ 


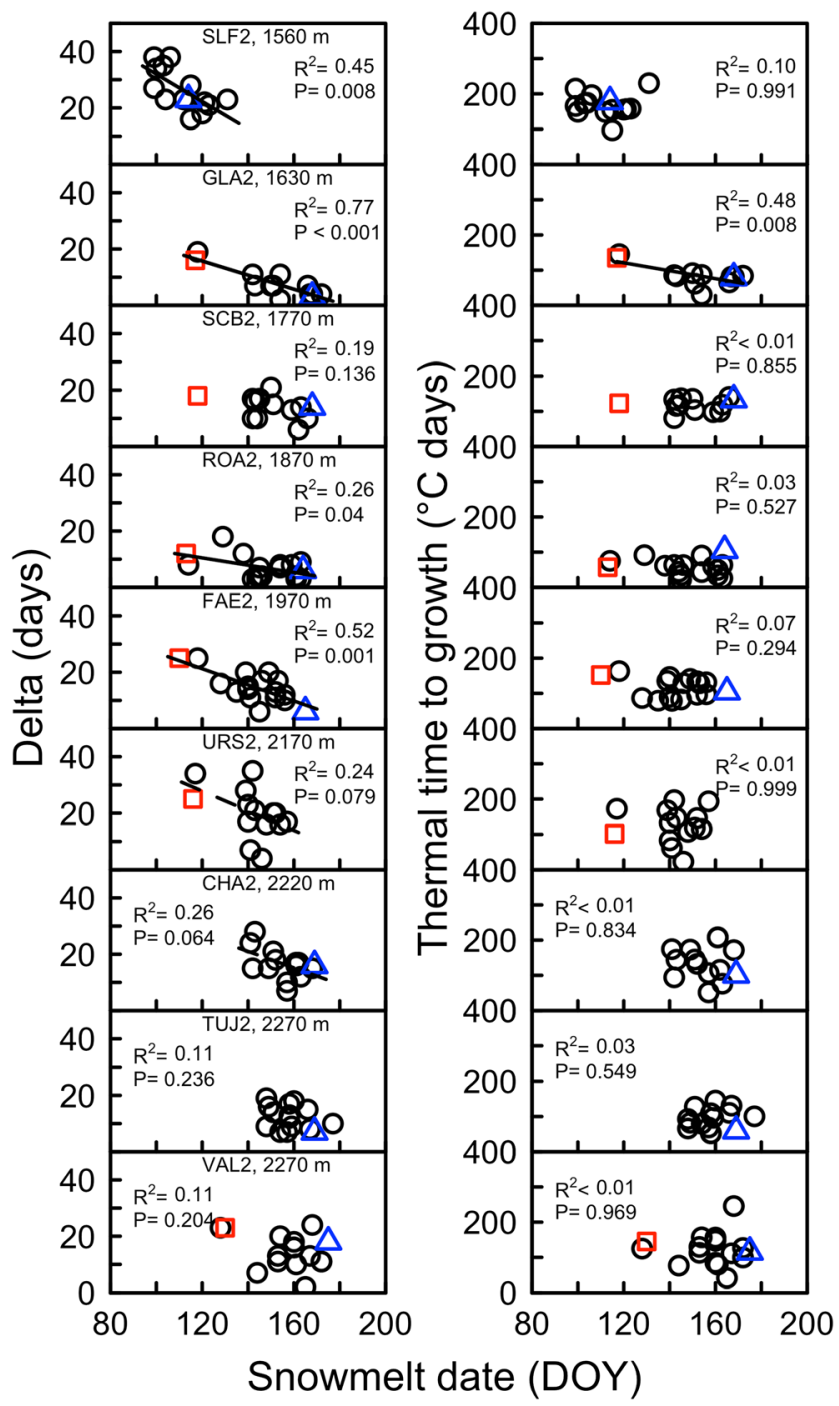

Fig. 8 Linear relationships between (1) the time lag from snowmelt date to vegetation onset $(\Delta)$ and snowmelt dates, (2) between the thermal time $>0{ }^{\circ} \mathrm{C}$ accumulated from snowmelt to vegetation onset and snowmelt dates for the nine individual stations having the most available data. Only stations having more than 12 years of phenology data are represented. Stations are sorted by their elevation as a photoperiod effect is more expected in low-elevation stations with early snowmelt. Note that Table 1 shows statistics of the linear regressions for all stations. The year 2011 is represented in red and the year 2013 is represented in blue. For black and white print: The year 2011 is represented with squares and the year 2013 with triangles

alpine plants (e.g., Körner 2003; Scherrer and Körner 2010). Even when temperature is directly measured at a study site in standard conditions (i.e., $2 \mathrm{~m}$ height under shelter), it can substantially vary from the actual temperature that is experienced by short-stature alpine plants. Hence, it is largely assumed that standard weather stations do not reflect well the temperature that prevails at plant height, especially minimum temperatures (Kollas et al. 2014; Körner 2003). Ground and plant temperature can also be much colder than air temperature during clear nights, due to radiative cooling (Inouye
2000) and much warmer during sunny days. In this study, temperature sums were calculated using air temperatures recorded at a $7 \mathrm{~m}$ height which might deviate from temperatures a few centimetres above the ground. However, all the weather stations used in this study were built to detect the snow cover and were therefore mounted in flat terrains preventing an important mismatch between surface ground and air temperature due to variations in the microtopography.

\section{Alpine plant phenology under global warming; is there a photoperiod limitation?}

A longer time lag was detected between snowmelt and vegetation onset when snowmelt occurred earlier (i.e., at lowelevation sites or during warmer springs). The increasing time required for the vegetation onset with earlier snowmelt could be the result of two causes: (i) a photoperiodic limitation preventing the plants from frost damage and (ii) a nonproportional increase of temperature over time, that is, late vegetation onset is likely to occur when temperatures are warmer than temperatures that occur earlier in the season at lower elevations. Overall, our results support mainly the second hypothesis since no significant increase of growing degree days required for vegetation onset was detected towards earlier dates of snowmelt. This is true in $95 \%$ of the study sites, even during exceptionally warm springs such as those that occurred in 2007 and 2011. Hence, spring phenology of alpine plants is tracking snowmelt patterns and temperature irrespective of elevation and the degree of warming. This suggests that, at the community level, alpine plants could be fully able to utilize periods of earlier snowmelt induced by global warming without a pronounced limitation induced by shorter daylength at the time of snowmelt. However, an increase of the thermal time with the advance of snowmelt was found in three sites located at low elevations (below $1800 \mathrm{~m}$ ). The vegetation tracked by the ultrasonic sensors at these sites may be responding to photoperiod to initiate its development in spring and may therefore be less sensitive to climate warming. Interestingly, the same dominant species occur in two of these three sites: Rumex alpinus (Alpine dock, station ALI2 and GLA2), whereas at the third station (STH2) the dominant species is represented by Ranunculus aconitifolius (Buttercup, Table S2). Further investigation would be necessary to test whether the phenology of these two species is controlled by photoperiod. Our study may have underestimated the proportion of species for which photoperiod is an important factor to initiate their growth because the signals detected by the ultrasonic sensors may correspond to tall and fast-growing species only, which are the ones expected to be the most sensitive to warming and the least responsive to photoperiod. In contrast, slow-growing plant species that might not have been detected by the ultrasonic sensors may have a lower sensitivity with regards to temperature and snowmelt change and a higher control by photoperiod. Besides, all the weather 
stations analysed in this study are located in flat terrain, in which snowbed plant species are expected to occur, while the effect of photoperiod has been shown to be more significant for species inhabiting wind-exposed areas, usually convex or steep terrains with less and irregular snow patterns (Hülber et al. 2010; Keller and Körner 2003). Hence, at current conditions in flat areas above $1800 \mathrm{~m}$ asl, photoperiod seems to not be a limiting factor in plant development even under unusually warm springs associated to early snowmelt conditions such as occurred in 2011. Furthermore, it is likely that, currently, the beginning of vegetation growth occurs late enough not to be limited by a photoperiod constraint. Most of alpine plants start their development only a few days before the maximum daylength, that is, the summer solstice on 21 st of June. For instance, the average date of vegetation onset found here across all sites and years was on the day 161 (i.e., 10th of June). However, extreme early snowmelt together with warmer air temperature, as is expected by the end of the century, could expose the plants to a time window for which photoperiod may become inadequate. As a result, a nonlinear change in phenology may be expected in response to earlier snowmelt and temperature rise in the longer term under continued climate warming (Iler et al. 2013), as currently observed in temperate and boreal trees (Fu et al. 2015b). For a better understanding of how climate warming is going to affect plant fitness, we encourage further investigations focused on the effect of warmer temperatures on the timing of flowering and seed production, in relation to warmer temperatures (Iler and Inouye 2013). For instance, Scheepens and Stöcklin (2013) showed for Campanula thyrsoides that, when transplanted towards lower elevations, the beginning of growth started well earlier, in line with our results, but also produced substantially fewer flowers and so likely reduced their fitness.

Our analysis also revealed that the heat required to trigger vegetation growth substantially varies among the sites, likely reflecting species-specific heat requirement for growth with no apparent correlation to elevation. We attribute the difference in heat requirement among sites to different compositions of the local vegetation (Table S2).

\section{Conclusion}

This study shows that, under current climatic conditions, alpine plants respond quickly and directly to earlier snowmelt and increasing temperature in a linear way without a significant control of photoperiod over the timing of vegetation onset in the vast majority of the study sites above $1800 \mathrm{~m}$ asl. Any change in the snowmelt timing has a strong impact on the surrounding air temperature experienced by alpine plants and therefore dramatically impacts their spring phenology, confirming earlier results conducted by Hülber et al. (2010) in the Austrian Alps at $2650 \mathrm{~m}$ asl. Alpine vegetation will therefore undergo earlier exposure to warm temperatures because snowmelt is expected to occur earlier under climate change, which would enhance the sole effect of warmer temperatures. This is why alpine vegetation might respond more to climate warming than lowland vegetation. Consequently, the phenology of alpine vegetation is likely to respond rapidly at sites with warmer temperatures and earlier snowmelt due to climate change, especially in snowbed habitats. Finally, the method developed here to extract the sensors' detection of vegetation growth could be extended to other meteorological networks using ultrasonic sensors all over the globe, opening promising avenues to explore how alpine or arctic vegetation will respond to global warming worldwide.

Acknowledgments We are grateful to Marcel Schoch and Christoph Marty for their assistance in providing climate parameters from the IMIS weather stations and to Andreas Scharl and André Fichtner for their field assistance with the vegetation surveys at the weather stations. We thank Andreas Stoffel for drawing the map of the selected stations shown in Fig. 1. We are grateful to David Inouye for his valuable comments on the manuscript and William Doehler for his editorial improvements of the manuscript. The research leading to these results has been funded by the Swiss National Science Foundation (grant number 200021-152954).

\section{References}

Anderson JT, Inouye DW, McKinney AM, Colautti RI, Mitchell-Olds T (2012) Phenotypic plasticity and adaptive evolution contribute to advancing flowering phenology in response to climate change. Proceedings of the Royal Society B-Biological Sciences 279: $3843-3852$

Basler D (2016) Evaluating phenological models for the prediction of leaf-out dates in six temperate tree species across Central Europe. Agric For Meteorol 217:10-21

Basler D, Körner C (2012) Photoperiod sensitivity of bud burst in 14 temperate forest tree species. Agric For Meteorol 165:73-81

Bjorkman AD, Elmendorf SC, Beamish AL, Vellend M, Henry GH (2015) Contrasting effects of warming and increased snowfall on Arctic tundra plant phenology over the past two decades. Glob Chang Biol 21:4651-4661

Böhm R, Auer I, Brunetti M, Maugeri M, Nanni T, Schöner W (2001) Regional temperature variability in the European Alps: 1760-1998 from homogenized instrumental time series. Int J Climatol 21:1779 1801

CaraDonna PJ, Inouye DW (2015) Phenological responses to climate change do not exhibit phylogenetic signal in a subalpine plant community. Ecology 96:355-361

Chen X, An S, Inouye DW, Schwartz MD (2015) Temperature and snowfall trigger alpine vegetation green-up on the world's roof. Glob Chang Biol 21:3635-3646

Clark JS, Salk C, Melillo J, Mohan J, Anten N (2014) Tree phenology responses to winter chilling, spring warming, at north and south range limits. Funct Ecol 28:1344-1355

Cornelius C, Leingärtner A, Hoiss B, Krauss J, Steffan-Dewenter I, Menzel A (2013) Phenological response of grassland species to manipulative snowmelt and drought along an altitudinal gradient. $\mathrm{J}$ Exp Bot 64:241-251

Efron B, Tibshirani RJ (1994) An introduction to the bootstrap. CRC press, New York: Chapman \& Hall 
Ernakovich JG, Hopping KA, Berdanier AB, Simpson RT, Kachergis EJ, Steltzer H, Wallenstein MD (2014) Predicted responses of arctic and alpine ecosystems to altered seasonality under climate change. Glob Chang Biol 20:3256-3269

Filippa G, Cremonese E, Galvagno M, Migliavacca M, di Cella UM, Petey M, Siniscalco C (2015) Five years of phenological monitoring in a mountain grassland: inter-annual patterns and evaluation of the sampling protocol. Int J Biometeorol 1-11

$\mathrm{Fu} \mathrm{YH}$ et al. (2015a) Increased heat requirement for leaf flushing in temperate woody species over 1980-2012: effects of chilling, precipitation and insolation. Glob Chang Biol 21:2687-2697

Fu YH et al. (2015b) Declining global warming effects on the phenology of spring leaf unfolding. Nature 526:104-107

$\mathrm{Fu}$ YSH et al. (2014) Variation in leaf flushing date influences autumnal senescence and next year's flushing date in two temperate tree species. Proc Natl Acad Sci 111:7355-7360

Gallinat AS, Primack RB, Wagner DL (2015) Autumn, the neglected season in climate change research. Trends Ecol Evol 30:169-176

Galvagno M et al. (2013) Phenology and carbon dioxide source/sink strength of a subalpine grassland in response to an exceptionally short snow season. Environ Res Lett 8:025008

Gobiet A, Kotlarski S, Beniston M, Heinrich G, Rajczak J, Stoffel M (2014) 21st century climate change in the European Alps-A review. Sci Total Environ 493:1138-1151

Gottfried $\mathrm{M}$ et al. (2012) Continent-wide response of mountain vegetation to climate change. Nat Clim Chang 2:111-115

Grabherr G, Gottfried M, Pauli H (1994) Climate effects on mountain plants. Nature 369:448-448

Hernández-Henríquez MA, Déry SJ, Derksen C (2015) Polar amplification and elevation-dependence in trends of Northern Hemisphere snow cover extent, 1971-2014. Environ Res Lett 10:044010

Hülber K, Winkler M, Grabherr G (2010) Intraseasonal climate and habitat-specific variability controls the flowering phenology of high alpine plant species. Funct Ecol 24:245-252

Iler AM, Høye TT, Inouye DW, Schmidt NM (2013) Nonlinear flowering responses to climate: are species approaching their limits of phenological change? Philosophical Transactions of the Royal Society of London B: Biological Sciences 368:20120489

Iler AM, Inouye DW (2013) Effects of climate change on mast-flowering cues in a clonal montane herb, Veratrum tenuipetalum (Melanthiaceae). Am J Bot 100:519-525

Inouye DW (2000) The ecological and evolutionary significance of frost in the context of climate change. Ecol Lett 3:457-463

Inouye DW (2008) Effects of climate change on phenology, frost damage, and floral abundance of montane wildflowers. Ecology 89:353-362

Jonas T, Rixen C, Sturm M, Stoeckli V (2008) How alpine plant growth is linked to snow cover and climate variability. Journal of Geophysical Research: Biogeosciences 113:G03013

Julitta $\mathrm{T}$ et al. (2014) Using digital camera images to analyse snowmelt and phenology of a subalpine grassland. Agric For Meteorol 198199:116-125

Keller F, Körner C (2003) The role of photoperiodism in alpine plant development. Arct Antarct Alp Res 35:361-368

Kimball SL, Bennett BD, Salisbury FB (1973) The growth and development of montane species at near-freezing temperatures. Ecology 168-173

Kollas C, Randin CF, Vitasse Y, Körner C (2014) How accurately can minimum temperatures at the cold limits of tree species be extrapolated from weather station data? Agric For Meteorol 184:257-266

Körner C (2003) Alpine plant life, 2nd edn. Springer, Berlin

Laternser M, Schneebeli M (2003) Long-term snow climate trends of the Swiss Alps (1931-99). Int J Climatol 23:733-750

Laube J, Sparks TH, Estrella N, Höfler J, Ankerst DP, Menzel A (2014) Chilling outweighs photoperiod in preventing precocious spring development. Glob Chang Biol 20:170-182
Livensperger C, Steltzer H, Darrouzet-Nardi A, Sullivan PF, Wallenstein M, Weintraub MN (2016) Earlier snowmelt and warming lead to earlier but not necessarily more plant growth. AoB Plants 8:plw021

Meehl GA et al. (2007) Global climate projections. In: Climate Change 2007: The Physical Science Basis. Contribution of Working Group I to the Fourth Assessment Report of the Intergovernmental Panel on Climate Change. Cambridge University Press, Cambridge, UK and New York, NY, USA

Mountain Research Initiative EDWWG (2015) Elevation-dependent warming in mountain regions of the world. Nature Clim Change $5: 424-430$

Parmesan C (2006) Ecological and evolutionary responses to recent climate change. Annual Review of Ecology Evolution and Systematics 37:637-669

Parolo G, Rossi G (2008) Upward migration of vascular plants following a climate warming trend in the Alps. Basic and Applied Ecology 9: $100-107$

Pauli H et al. (2012) Recent plant diversity changes on Europe's mountain summits. Science 336:353-355

Petraglia A, Tomaselli M, Petit Bon M, Delnevo N, Chiari G, Carbognani M (2014) Responses of flowering phenology of snowbed plants to an experimentally imposed extreme advanced snowmelt. Plant Ecol 215:759-768

R Core Team (2015) cianR: A language and environment for statistical computing. R Foundation for Statistical Computing, Vienna, Austria. http://www.R-project.org/

Rebetez M, Reinhard M (2008) Monthly air temperature trends in Switzerland 1901-2000 and 1975-2004. Theor Appl Climatol 91: 27-34

Reid PC et al. (2016) Global impacts of the 1980s regime shift. Glob Chang Biol 22:682-703

Scheepens JF, Stöcklin J (2013) Flowering phenology and reproductive fitness along a mountain slope: maladaptive responses to transplantation to a warmer climate in Campanula thyrsoides. Oecologia 171: 679-691

Scherrer D, Körner C (2010) Infra-red thermometry of alpine landscapes challenges climatic warming projections. Glob Chang Biol 16: 2602-2613

Scherrer SC, Appenzeller C (2006) Swiss Alpine snow pack variability: major patterns and links to local climate and large-scale flow. Clim Res 32:187-199

Sedlacek J et al. (2016) Evolutionary potential in the Alpine: trait heritabilities and performance variation of the dwarf willow Salix herbacea from different elevations and microhabitats. Ecol Evol:in press

Sedlacek J et al. (2015) The response of the alpine dwarf shrub Salix herbacea to altered snowmelt timing: lessons from a multi-site transplant experiment. PLoS One 10:e122395

Serquet G, Marty C, Dulex JP, Rebetez M (2011) Seasonal trends and temperature dependence of the snowfall/precipitation-day ratio in Switzerland. Geophys Res Lett 38

Serquet G, Marty C, Rebetez M (2013) Monthly trends and the corresponding altitudinal shift in the snowfall/precipitation day ratio. Theor Appl Climatol 114:437-444

Wahren CHA, Walker MD, Bret-Harte MS (2005) Vegetation responses in Alaskan arctic tundra after 8 years of a summer warming and winter snow manipulation experiment. Glob Chang Biol 11:537-552

Walker DA, Halfpenny JC, Walker MD, Wessman CA (1993) Long-term studies of snow-vegetation interactions. Bioscience 43:287-301

Walther G-R (2003) Plants in a warmer world. Perspectives in plant ecology, evolution and systematics 6:169-185

Wheeler JA et al. (2016) The snow and the willows: earlier spring snowmelt reduces performance in the low-lying alpine shrub Salix herbacea. J Ecol:in press

Wheeler JA, Hoch G, Cortés AJ, Sedlacek J, Wipf S, Rixen C (2014) Increased spring freezing vulnerability for alpine shrubs under early snowmelt. Oecologia 175:219-229 
Wielgolaski FE, Inouye DW (2013) Phenology at high latitudes. In: Schwartz MD (ed) Phenology: an integrative environmental science. Springer, pp 225-247

Wipf S, Rixen C (2010) A review of snow manipulation experiments in Arctic and alpine tundra ecosystems. Polar Res 29:95-109
Wipf S, Stoeckli V, Bebi P (2009) Winter climate change in alpine tundra: plant responses to changes in snow depth and snowmelt timing. Clim Chang 94:105-121

Zohner CM, Renner SS (2015) Perception of photoperiod in individual buds of mature trees regulates leaf-out. New Phytol 208:1023-1030 